Tohoku J. exp. Med., 1973, 110, 367-375

\title{
Responses of the Canine Splenic Vascular Bed to Various Biogenic and Foreign Substances
}

\author{
Susumu Satoh* and Koroku Hashimoto \\ Department of Pharmacology, Tohoku University School of \\ Medicine, Sendai
}

\begin{abstract}
Sato, S. and Hashimoto, K. Responses of the Canine Splenic Vascular Bed to Various Biogenic and Foreign Substances. Tohoku J. exp. Med., 1973, 110 (4), 367-375 - Responses of dog splenic vascular bed to various compounds administered into the splenic artery were investigated under a constant perfusion pressure. Adrenergic drugs; epinephrine, norepinephrine and dopamine produced a marked vasoconstriction which was followed by a vasodilation. Phenylephrine, tyramine, methoxamine and ephedrine produced only vasoconstriction. Isoproterenol dilated the splenic vascular bed. Cholinergic drugs; cholinesters and pilocarpine caused a vasodilation, while physostigmine produced a vasoconstriction. Ganglion stimulants; MeN-A-343, TMA and lobeline produced a vasodilation, while DMPP and nicotine caused a vasoconstriction. TEA, one of ganglion blockers, caused a vasoconstriction. Angiotensin II, lys-vasopressin, oxytocin and 5-hydroxytryptamine produced a vasoconstriction. Bradykinin, kallikrein and histamine caused a vasodilation. Various nucleosides and nucleotides, i.e., adenosine, AMP, ADP, ATP, uridine, UMP, UDP, UTP, DPN and TPN induced peculiar oscillatory vascular responses. Vasodilators including nitroglycerin, papaverine, verapamil, dipyridamole, hydralazine and caffeine dilated the splenic vascular bed, while cocaine, guanethidine and ergotamine constricted it. Procaine, morphine, bretylium, tolazoline showed a vasodilation. These results indicated that the splenic vascular bed has a very characteristic behavior.

splenic vascular bed; vasoactive substance; oscillatory vascular response
\end{abstract}

A considerable amount of investigations on the splenic vascular bed has been performed on various kinds of autonomic drugs. Especially, the effects of epinephrine and norepinephrine have been extensively studied in this organ. However, little information is available concerning the responses to other vasoactive substances. On the other hand, Hashimoto and Kumakura (1965) investigated the pharmacological features of the coronary, renal, mesenteric and femoral vascular beds in the dog, and Matsumura et al. (1968) and Yamamoto et al. (1970) advanced such a comparative study further to the canine vesical and saphenous vasculature respectively. These studies demonstrated that each peripheral artery responded differently to various substances administered intra-arterially. The present authors perfused the canine splenic artery with blood conducted from the femoral artery under a constant perfusion pressure. Drugs were given close-arterially in order to

Received for publication, January 18, 1973.

* Present address: Department of Pharmacology, Akita University School of Medicine, Akita. 
investigate the pharmacological feature of the splenic artery.

\section{METHODS}

Twenty mongrel dogs of both sexes, weighing from 8 to $14 \mathrm{~kg}$, were anesthetized with $30 \mathrm{mg} / \mathrm{kg}$ of sodium pentobarbital intravenously. The supranavel abdomen was opened by a median incision. Surgical procedures and experimental set up were essentially the same as those in a previous paper (Hashimoto and Satoh 1971).

All branches of the splenic artery to the stomach, to the pancreas and to the greater omentum were ligated. The trunk of the splenic artery divided in two main branches at the hilus lienalis. Animal's own blood led from the femoral artery was perfused into two main branches of the splenic artery through polyethylene cannula $(3 \mathrm{~mm}$, o.d.) by the aid of a perfusion pump (Harvard Apparatus Model, 505-1200). A pneumatic resistance of $100 \mathrm{~mm} \mathrm{Hg}$ was set in parallel with the perfusion system and the blood flow was constantly bypassed through this resistance to the femoral vein. By this means the perfusion pressure was kept at $100 \mathrm{~mm} \mathrm{Hg}$ throughout the experiment. The systemic blood pressure in the carotid artery and the perfusion pressure were measured by pressure transducers (Nihon Kohden, MP-4T). The flow rate of the splenic artery was measured by an electromagnetic flowmeter (Nihon Kohden, MF-2-a). The blood coagulation was prevented by administration of $500 \mathrm{units} / \mathrm{kg}$ of sodium heparin at the beginning of perfusion and an additional dose of 1,000 units was given at one hour intervals. For administration of drug solution, microinjector (Jintan Thermo Co.) was used and a volume of $0.03-0.1 \mathrm{ml}$ of drug solution was injected into the rubber tube connected closely to the shank of the arterial cannula in a period of $10 \mathrm{sec}$.

Drugs used are listed in Table 1. l-Epinephrine and $l$-norepinephrine were dissolved in $0.01 \mathrm{~N} \mathrm{HCl}$ at a concentration of $1 \mathrm{mg} / \mathrm{ml}$ as stock solution. Drugs were dissolved in a desired concentration with $0.9 \%$ saline.

\section{Results}

\section{Control observations}

The blood flow in the splenic artery maintained a steady level of $18.5 \pm 1.7$ $\mathrm{ml} / \mathrm{min}$ (mean \pm s.E., $\mathrm{n}=20$ ) at $100 \mathrm{~mm} \mathrm{Hg}$ of perfusion pressure. The average weight of the spleen measured at the end of each experiment was $48.5 \pm 6.4 \mathrm{~g}$. The flow rate per unit of wet weight was $41.3 \pm 5.2 \mathrm{ml} / 100 \mathrm{~g} / \mathrm{min}$.

\section{Adrenergic drugs (Fig. 1)}

Epinephrine, norepinephrine and dopamine caused a vasoconstriction which was followed by a vasodilation. Among them norepinephrine produced the most prominent vasoconstriction. The secondary vasodilation was the most prominent in the response to epinephrine. Phenylephrine, tyramine, methoxamine and ephedrine caused a vasoconstriction, while isoproterenol produced a dilation. Tyramine and ephedrine were approximately $1 / 100$ in their activity as compared with that of norepinephrine.

\section{Cholinergic drugs (Fig. 2)}

Acetylcholine, bethanechol, carbachol and methacholine dilated the splenic vascular bed. Among them carbachol caused the most prominent vasodilation, 
TABLE 1. Ranges of doses of investigated drugs

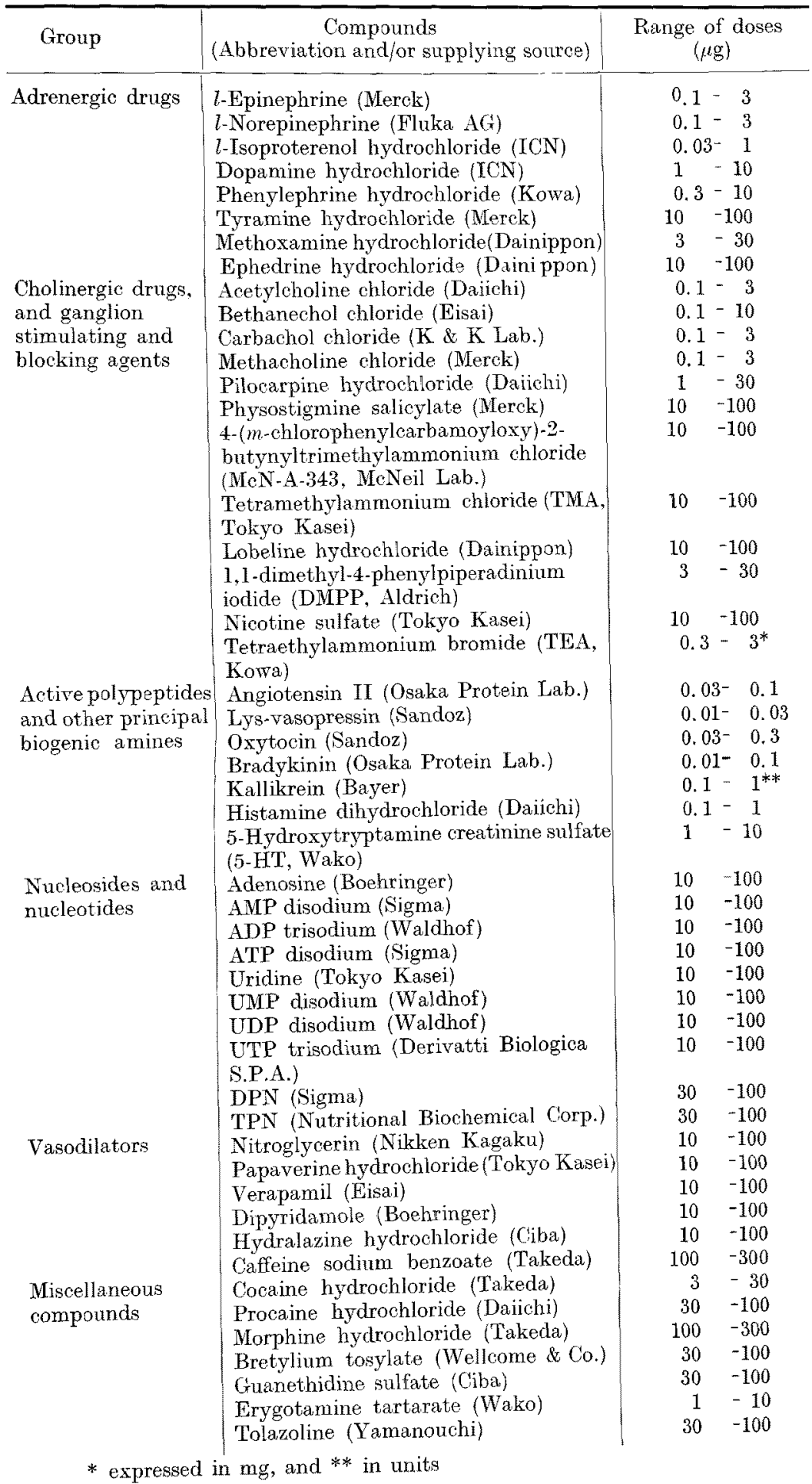




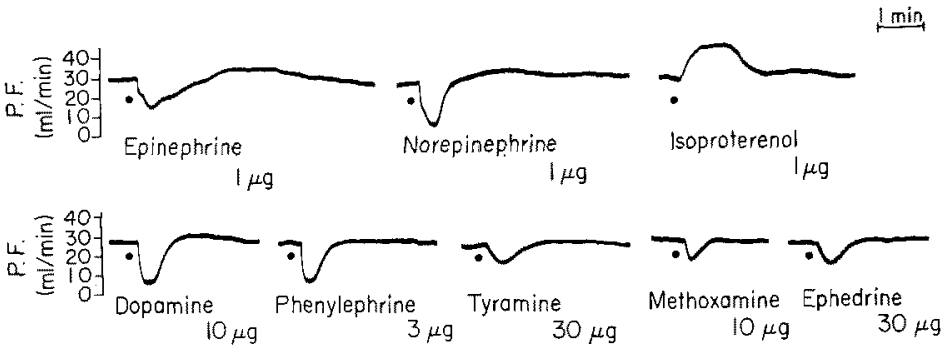

Fig. 1. Responses to adrenergic drugs of splenic vascular bed. P.F. stands for perfusion flow.

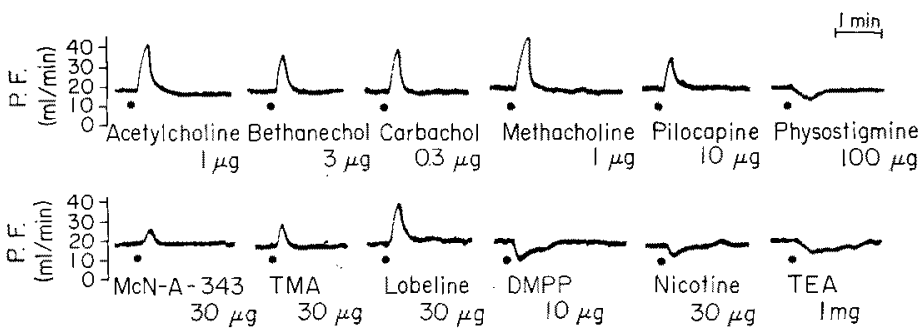

Fig. 2. Responses to cholinergic drugs and ganglion stimulants and blocking agent of splenic vascular bed.

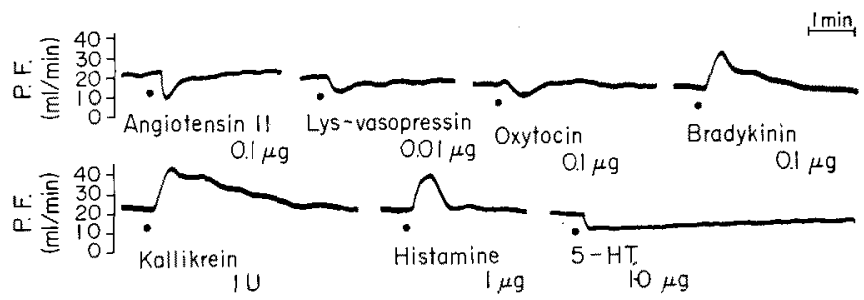

Fig. 3. Responses to active polypeptides and biogenic amines of splenic vascular bed.

and acetylcholine and methacholine were almost equal in the activity. Pilocarpine also dilated the splenic vascular bed. The vascular response to physostigmine was transient constriction even in a fairly large dose.

\section{Ganglionic stimulants and blocking agents (Fig. 2)}

Among ganglionic stimulants, McN-A-343, TMA and lobeline caused a vasodilation, while nicotine and DMPP induced a vasoconstriction. TEA, one of ganglionic blockers, caused a vasoconstriction in a fairly large dose.

5. Active peptides and other principal biogenic amines (Fig. 3)

Angiotensin II, lys-vasopressin and oxytocin induced a vasoconstriction. Lys-vasopressin was the most active among them. Bradykinin and kallikrein dilated the splenic vascular bed. Histamine caused a vasodilation, while 5- 

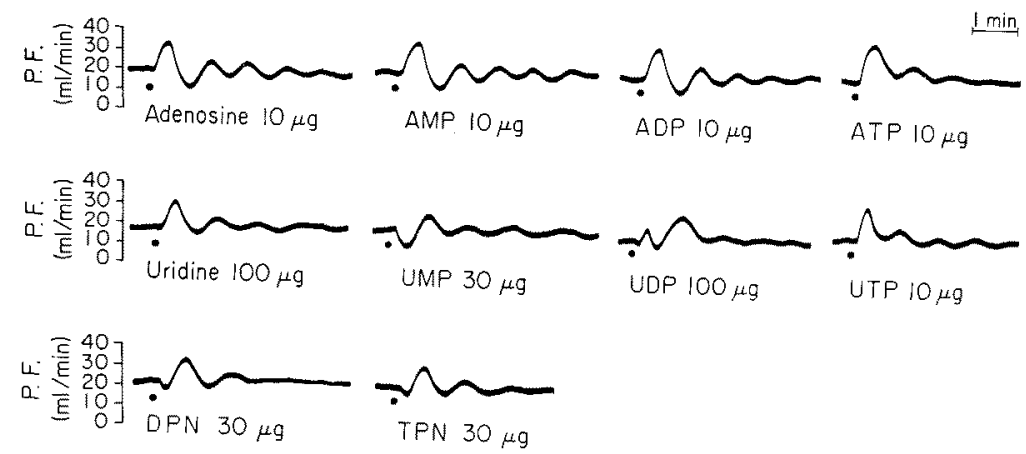

Fig. 4. Responses to mucleosides and nucleotides of splenic vascular bed. Note the oscillatory vascular responses to these compounds.
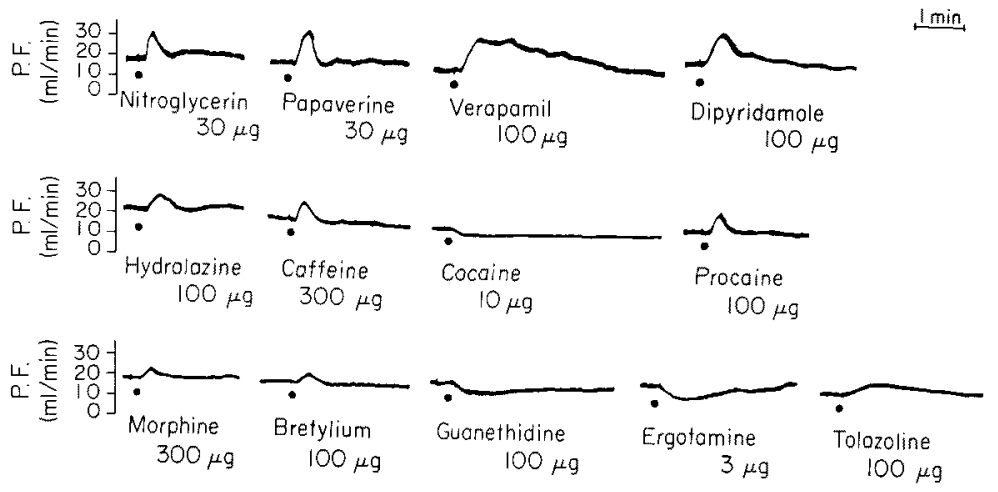

Fig. 5. Responses to vasodilators and miscellaneous compounds of splenic vascular bed.

hydroxytryptamine induced a long-lasting constriction of the splenic vascular bed.

\section{Nucleosides and nucleotides (Fig. 4)}

The splenic vascular bed showed characteristic pharmacological responses to nucleosides and nucleotides, i.e., oscillatory changes in the flow rate. Adenosine, AMP, ADP, uridine, UDP, ATP and UTP produced an initial increase of the splenic blood flow which then oscillated up and down on the starting level with former five compounds, while ATP and UTP also caused an oscillation during vasodilator response. Such undulatory changes in the blood flow gradually disappeared. Among them adenosine and AMP elicited the most prominent oscillation. UMP, DPN and TPN produced an initial vasoconstriction which was followed by vasodilation and oscillatory vascular response. The initial vasoconstriction was the most evident in the response to UMP.

7. Vasodilators (Fig. 5)

Nitroglycerin, papaverine, verapamil, dipyridamole, hydralazine and caffeine 
TABLE 2. Classification of investigated drugs in comparison with their effects on

\begin{tabular}{|c|c|c|c|c|c|}
\hline & (a) & (b) & \multicolumn{3}{|c|}{ (c) } \\
\hline Coronary artery & Dil. & Dil. & \multicolumn{3}{|c|}{ Dil. } \\
\hline Renal artery & Dil. & Const. & \multicolumn{3}{|c|}{ Const. } \\
\hline Mesenteric artery & Dil. & Dil. & \multicolumn{3}{|c|}{ Const. } \\
\hline Femoral artery & Dil. & Dil. & \multicolumn{3}{|c|}{ Dil. } \\
\hline Vesical artery & Dil. & Dil. & \multicolumn{3}{|c|}{ Dil. } \\
\hline Saphenous artery & Dil. & Dil. & Const. & \multicolumn{2}{|c|}{ Dil. } \\
\hline \multirow[t]{2}{*}{ Splenic artery } & Dil. & Dil. & Const. & Const. & Dil. \\
\hline & $\begin{array}{l}\text { ATP* } \\
\text { ADP* } \\
\text { UTP* } \\
\text { Bradylinin } \\
\text { Kallikrein } \\
\text { Acetylcholine } \\
\text { Histamine } \\
\text { Isoproterenol } \\
\text { Papaverine } \\
\text { Nitroglycerin }\end{array}$ & $\begin{array}{l}\text { AMP* } \\
\text { Adenosine* } \\
\text { UDP* } \\
\text { Dipyridamole }\end{array}$ & DMPP & Nicotine & $\begin{array}{l}\text { Lobeline } \\
\text { Hydralazine }\end{array}$ \\
\hline
\end{tabular}

dilated the splenic vascular bed. The vasodilation caused by verapamil was extremely long in duration in comparison with those produced by other vasodilators.

\section{Miscellaneous componnds (Fig. 5)}

Procaine and morphine dilated the splenic vascular bed, while cocaine elicited a sustained vasoconstriction. The splenic vasculature responded to guanethidine simply with a constriction, while it responded to bretylium with dilation. Ergotamine and tolazoline, $a$-adrenergic blocking agents, responded differently in the splenic vascular bed. The former elicited a vasoconstriction, while the latter caused a vasodilation.

\section{Discussion}

Hashimoto and Kumakura (1965), Matsumura et al. (1968) and Yamamoto et al. (1970) classified a variety of drugs according to their pharmacological actions on the coronary, renal, mesenteric, femoral, vesical and saphenous vascular beds. Comparing our results with theirs, the behavior of the splenic vasculature was different from any of the above mentioned vascular beds. In Table 2 the pharmacological features of the splenic vasculatures are added to the classification which was proposed by Hashimoto and Kumakura (1965), Matsumura et al. (1968) and Yamamoto et al. (1970). Nucleosides and nucleotides caused an oscillatory response in the splenic vascular bed. Therefore, vascular response to these compounds 
the coronary, renal, mesenteric, femoral, vesical, suphenous and splenic vascular beds

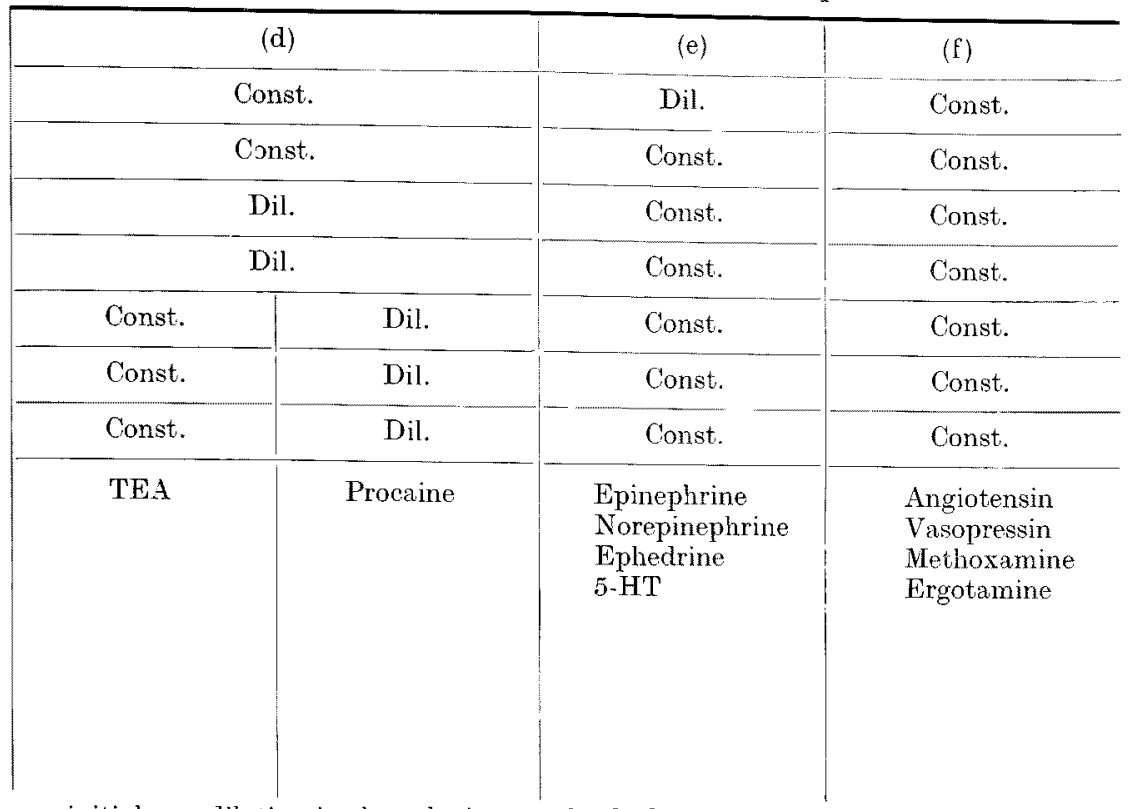

an initial rasodilation in the splenic vascular bod.

was expressed as the initial response in Table 2. The pharmacological characteristics of the splenic vascular bed are distinct from those of the mesenteric artery in the responses to lobeline, hydralazine and TEA. Lobeline and hydralazine dilated the splenic artery but constricted the mesenteric artery, while TEA constricted the splenic artery but dilated the mesenteric artery. The vasodilation following vasoconstriction to epinephrine and norepinephrine may be due to tneir $\beta$-receptor stimulation in the splenic vascular smooth muscle as proposed by Davis et al. (1969). The vasoconstrictor response to norepinephrine was found to be more active than that to epinephrine, which coincided with the finding by Greenway and Stark (1970). The blood vessels are in general dilated by physostigmine (Koelle 1970), although the splenic vascular bed responded to physostigmine with a constriction. The vasoconstriction to physostigmine was observed in the coronary and pulmonary circulation (Koelle 1970). DMPP, nicotine and TEA were known to increase the release of norepinephrine from the sympathetic nerve endings (Burn et al. 1959; Lindmar and Musholl 1961; Thoenen et al. 1967). Therefore, it is reasonable to consider that the vasoconstrictor responses to DMPP, nicotine and TEA were due to the release of norepinephrine from the sympathetic nerve endings in the spleen.

The oscillatory vascular response to nucleosides and nucleotides was a characteristic phenomenon in the splenic vasculature. Among them, oscillation started following an initial vasoconstriction by the administration of UMP, DPN and TPN, while an initial vasodilation was observed with adenosine, AMP, ADP, ATP, UTP and uridine. 
Barcroft and Nishimaru (1932) considered the oscillatory changes in the splenic volume might be responsible for induction of undulatory changes in the systemic blood pressure. However, Grindlay et al. (1939) concluded that the oscillatory change originated from the splenic vascular response and not from the change of smooth muscle tone of the splenic capsule. The characteristic ascillation can be initiated by the release of occlusion of the splenic artery and our previous investigation showed the enhancement of the diminished post-occlusive oscillatory vascular response by the administration of adenosine (Hashimoto and Satoh 1971). A certain vasoactive substance such as adenosine or catecholamine or AMP is produced in the sequence of the tissue metabolism and it accumulates in the tissue where the circulation is occluded (Imai et al. 1964). Such active metabolite is released into the blood stream immediately after the release of occlusion, which causes a distinct vascular response such as reactive hyperaemia in the coronary circulation (Miura et al. 1967) or reactive ischaemia in the kidney (Scott et al. 1965; Sakai et al. 1968). As shown in the results of this report, the oscillatory response of the splenic artery is observed by the intra-arterial administration of nucleosides and nucleotides. It is worthy to note that the splenic vasculature responded to the post-occlusion and nucleosides and nucleotides with the same pattern of characteristic oscillation. The responses to nucleosides and nucleotides are consistent with the observation in the previous paper suggesting that adenosine might probably play an important role for the post-occlusive oscillation in the splenic circulation (Hashimoto and Satoh 1971).

\section{References}

1) Bareroft, J. \& Nisimaru, Y. (1932) Cause of rhythmical contraction of the spleen. J. Physiol., 74, 299-310.

2) Burn, J.H., Leach, E.H., Rand, M.J. \& Thompson, J.W. (1959) Peripheral effects of nicotine and acetylcholine resembling those of sympathetic stimulation. $J$. Physiol, 148, $332-352$.

3) Davies, B.N., Robinson, B.H. \& Withrington, P.G. (1969) The effects of graded doses of phenoxybenzamine on the vascular and capsular responses of the isolated, blood-perfused dogs spleen to sympathetic nerve stimulation and catecholamines. Arch. int. Pharmucodyn., 180, 143-154.

4) Greenway, C.V. \& Stark, R.D. (1970) The vascular responses of the spleen to intravenous infusions of catecholamines, angiotensin and vasopressin in the anaesthetized cat. Brit. J. Pharmacol., 38, 583-592.

5) Grindlay, J.H., Herrick, J.F. \& Baldes, E.J. (1939) Rhythmicity of the spleen in relation to blood flow. Amer. J. Physiol., 127, 119-126.

6) Hashimoto, K. \& Kumakura, S. (1965) The pharmacological features of the coronary, renal, mesenteric and femoral arteries. Jap. J. Physiol., 15, 540-551.

7) Hashimoto, K. \& Satoh, S. (1971) Enhancement of the post-occlusive oscillation in the splenic circulation by adenosine. J. Physiol., 218, 295-304.

8) Imai, S., Riley, A.L. \& Berne, R.M. (1964) Effect of ischemia on adenine nucleotides in cardiac and skeletal muscle. Circulat. Res., 15, 443-449.

9) Koelle, G.B. (1970) Anticholinesterase agents. In: The Pharmacological Basis of Therapeutics., edited by L.S. Goodman \& S. Gilman, Macmillan, New York, 4th edition, pp. $442-465$.

10) Lindmar, R. \& Muscholl, E. (1961) Die Wirkung von Cocain, Guanethidin, Reserpin, 
Hexamethonium, Tetracain und Psicain auf die Noradrenalin-Freisetzung aus dem Herzen. Naunyn-Schmiedeberg's Arch. exp. Path. Pharmak, 242, 214-227.

11) Matsumura, S., Taira, N. \& Hashimoto, K. (1968) The pharmacological behavior of the urinary bladder and its vasculature of the dog. Tohoku J. exp. Med., 96, 247258.

12) Miura, M., Tominaga, S. \& Hashimoto, K. (1967) Potentiation of reactive hyperemia in the coronary and femoral circulation by the selective use of 2,6 -bis (diethanolamino) -4,8-dipiperidino-pyrimido (5,4-d)-pyrimidine. Arzneimittel-Forsch., 17, 976-979.

13) Sakai, K., Yasuda, K. \& Hashimoto, K. (1968) Role of catecholamine and adenosine in the ischemic response following release of a renal artery occlusion. Jap. J. Physiol., 18, 673-685.

14) Scott, J.B., Daugherty, R.M., Jr., Dabney, J.M. \& Haddy, E.J. (1965) Role of chemical factors in regulation of flow through kidney, hindlimb, and heart. Amer. J. Physiol., 208, 813-824.

15) Thoenen, H., Haefely, W. \& Staehelin, H. (1967) Potentiation by tetraethylammonium of the response of the cat spleen to postganglionic sympathetic nerve stimulation. J. Pharmacol. exp. Therap., 157, 532-540.

16) Yamamoto, M., Sasaki, H., Taira, N. \& Hashimoto, K. (1970) Responses of the canine saphenous vascular bed to various biogenic and foreign substances. Tohoku J. $\exp$. Med., 101, 299-309. 